\title{
Student Activity and Sport Study Ireland: Protocol for a Web-Based Survey and Environmental Audit Tool for Assessing the Impact of Multiple Factors on University Students' Physical Activity
}

Joseph J Murphy ${ }^{1,2^{*}}$, PhD; Catherine B Woods ${ }^{1,2^{*}}, \mathrm{PhD}$; Marie H Murphy ${ }^{3 *}, \mathrm{PhD}$; Niamh Murphy ${ }^{4 *}, \mathrm{PhD}$; Neal Byrne ${ }^{4}$, MSc; Ciaran Mac Donncha ${ }^{1,2^{*}}, \mathrm{PhD}$

\footnotetext{
${ }^{1}$ Department of Physical Education and Sport Sciences, University of Limerick, Limerick, Ireland

${ }^{2}$ Health Research Institute, University of Limerick, Limerick, Ireland

${ }^{3}$ Sport and Exercise Sciences Research Institute, Ulster University, Newtownabbey, United Kingdom

${ }^{4}$ Department of Health Sciences, Waterford Institute of Technology, Waterford, Ireland

*these authors contributed equally
}

\section{Corresponding Author:}

Joseph J Murphy, PhD

Department of Physical Education and Sport Sciences

University of Limerick

Castletroy

Limerick,

Ireland

Phone: 353857375228

Email: Joey.Murphy@ul.ie

\section{Abstract}

Background: Increasing proportions of the global population transition through a university setting, a setting associated with engagement in behaviors that diminish health such as high levels of physical inactivity. Increasing physical activity (PA) is a key element of health promotion strategies in many countries, but a better understanding of students' PA and how it is associated with personal, behavioral, and environmental factors is needed. Studies provide protocols to collect information regarding these factors separately; however, none have developed a validated systematic approach to gather information pertaining to all across a whole country.

Objective: The purpose of this project is to examine students' physical activity and how it is associated with personal, behavioral, and environmental factors.

Methods: Student Activity and Sport Study Ireland (SASSI) is a university-based cross-sectional study that was carried out across the island of Ireland in 2014. A novel and comprehensive Web-based environmental audit tool (EAT) gathered information pertaining to the environment provided by universities for physical activity. A Web-based student survey (SS) collected information about physical activity beliefs, attitudes, motivations, and behaviors of students. The audit tool and SS were developed through rigorous consultation processes involving international experts. An institutional champion volunteered at each university to recruit, administer, and ensure the completion of both assessments.

Results: Data collection was undertaken between May and December 2014. A total of 80\% (33/41) of universities completed the EAT, whereas $88.31 \%$ (8122/9197) of students (49.10\% [3966/8122] male; mean 23.17 [SD 6.75], years) completed the SS sufficiently. Studies are currently underway with the data collected using this protocol.

Conclusions: SASSI provides a novel and comprehensive protocol for systematically assessing the PA of students and the related personal, behavioral, and actual environmental factors. The strengths of the SASSI study are presented and include high response rates and a unique dataset that can provide information to relevant stakeholders and policy makers, along with aiding the development of university environments and interventions that promote PA involvement. The weaknesses of the protocol are recognized with suggestions given to overcome them in future research. This protocol is applicable for other countries and has great potential to create harmonization of data, which would allow for direct comparisons across nations.

International Registered Report Identifier (IRRID): RR1-10.2196/10823 
(JMIR Res Protoc 2019;8(2):e10823) doi: 10.2196/10823

\section{KEYWORDS}

physical activity; universities; students; environment

\section{Introduction}

\section{Background}

Early adulthood (ie, ages 18-24 years) is regarded as an exploratory phase, which anchors health-related behaviors that often persist into later life and determine long-term health outcomes [1]. It is becoming increasingly popular for individuals to attend a university during early adulthood. The global student population exceeded 178 million in 2010 and is expected to reach 263 million by 2025 [2]. Research indicates a high proportion of university students engage in behaviors that diminish their health, such as high levels of physical inactivity (23\%-44\%) [3], and exceeding the daily recommended alcohol and tobacco smoking limits [4]. With students exposed to multiple health-related behaviors of both a positive and negative nature, it seems prudent to focus on a behavior known to benefit the physical, cognitive, and social health of individuals, such as physical activity (PA) [5]. The recommendation to increase PA is a key element of health promotion strategies in many countries [3], where PA includes sport, structured exercise, and active transport [6]. In the general population, PA is an important factor for the prevention of noncommunicable diseases such as obesity, cardiovascular heart diseases, and type 2 diabetes mellitus [7,8]. Although PA levels of children and adults across the globe are well documented [9], university students' behaviors, beliefs, and attitudes, and how these are formed and reinforced, require further research, particularly in representative or random samples [10].

Understanding the factors that relate to PA is a key step for developing effective evidence-based programs [11]. Social cognitive models have performed well for understanding the factors that relate to individuals' PA, with Bandura's social cognitive theory [12] seen as a popular choice for this purpose $[13,14]$. Social cognitive theory proposes an agentic perspective, suggesting that not only is the environment dictating behavior but also that individuals are being self-regulating and self-developing [12]. Social cognitive theory is founded on a causal model of triadic reciprocal causation in which personal factors, behavioral patterns, and environmental characteristics all interact and influence one another in a bidirectional fashion [12]. However, this theory has been said to focus mainly on the social environment and rarely address the multidimensional role of the physical environment [15].

For this reason, it seems appropriate to also use an ecological approach that summarizes the multiple levels of influence on a behavior, breaking them down into intrapersonal, interpersonal, physical environment, and policy [16]. Furthermore, research has noted the benefits of using social cognitive theory and ecological approaches in combination to investigate the factors relating to PA [17]. Research suggests that personal (eg, age, sex, attitudes, and knowledge of benefits), behavioral (eg, past PA and smoking), and environmental (eg, peer support and recreational PA opportunities) factors are associated with adults and students' PA [10,18]. Personal and behavioral factors relating to PA are much better understood in university students when compared with research examining associations between PA and the physical environment [10,19,20]. Research is needed to determine and better understand how the environment within which individuals spend time might act to enhance or constrain PA [20]. Our understanding of the impact of the university setting on students' PA is limited [21], but the physical environment has been shown to influence students' decision-making process regarding engagement in PA [17]. Nonetheless, evidence is lacking regarding the impact of institution size, support staff, extent and nature of facilities, financial investment, opportunities for participation, and institutional ethos and policy on students' PA participation.

\section{Objectives}

To date, studies provide protocols to collect both individual [22-24] and environmental information [25,26]; however, none have developed a validated systematic approach to gather information pertaining to the individual (ie, personal and behavioral) and environment across a whole country. Student Activity and Sport Study Ireland (SASSI), the first of its kind, addresses the important topic of the interaction between these factors and participation in PA on the island of Ireland. First, this study aimed to develop and create a comprehensive and usable audit tool for examining the environment, provision, and support offered by universities for students' PA participation. Second, it aimed to develop a survey to collect information regarding the level, type, and nature of PA participation by students, including the associated determinants, health-related behaviors, and outcomes. Finally, this study aimed to create a protocol, guided by social cognitive theory and an ecological approach that would allow for the audit tool and survey to be used together and provide a holistic view of the factors relating to university students' PA.

\section{Methods}

\section{General Information}

Guided by social cognitive theory and an ecological approach, SASSI is a university-based environmental audit tool (EAT) and student survey (SS), which was conducted in 2014. All universities $(n=41)$ on the island of Ireland were invited to partake in SASSI, with universities classified into the following categories, based on their size: (1) large $=\geq 11,000$ students; (2) medium $=4000$ to 10,999 students; and (3) small $=\leq 3999$ students. The university size was based on the distribution of the 2013 to 2014 full-time undergraduate and postgraduate enrollment figures across all universities [27,28]. The active partners in the study included the research team, the Student Sport Ireland (SSI) Research Management Group, and the institutional champions (ICs; Figure 1). SSI is the governing body of university sport in Ireland. Owing to the all-island approach, ethical clearance from relevant ethical committees in the 
Republic of Ireland (Waterford Institute of Technology School of Health Science Research Ethics Committee) and Northern Ireland (Ulster University Research Governance) was obtained and extended through recognition by all universities involved. Detailed information sheets about the study were provided before the start of the EAT and SS. Signed informed institutional consent was received for the EAT, and students were informed that they were providing consent when they chose to proceed with the SS. The data collection process used for the EAT and $\mathrm{SS}$ are presented in the coming sections and in Figure 2.

\section{Institutional Champions}

Given the extent of the study and the geographical spread of the universities, the research team relied heavily upon the voluntary contribution of ICs $(n=52)$. In the majority of cases, the IC was the designated contact person for SSI in each of the universities. The ICs were an integral part of the study; their key roles were to promote the research within their university, lead the completion of the EAT through engagement with other institutional stakeholders, and recruit for and administer the SS according to predetermined quotas. To maintain consistency across all universities and ensure the collection of valid data, each IC completed a half-day training program that was used to empower the IC to assist with sufficient data collection. Not only did this process ensure standardization in the implementation across each university, it also created an opportunity to build grassroots commitment and ownership in the study. A research manager was employed as part of the research team and was responsible for overall quality control and ensuring that the ICs were supported in their roles.

Figure 1. Active partners in Student Activity and Sport Study Ireland. SSI: Student Sport Ireland.

\section{SSI research}

management

group
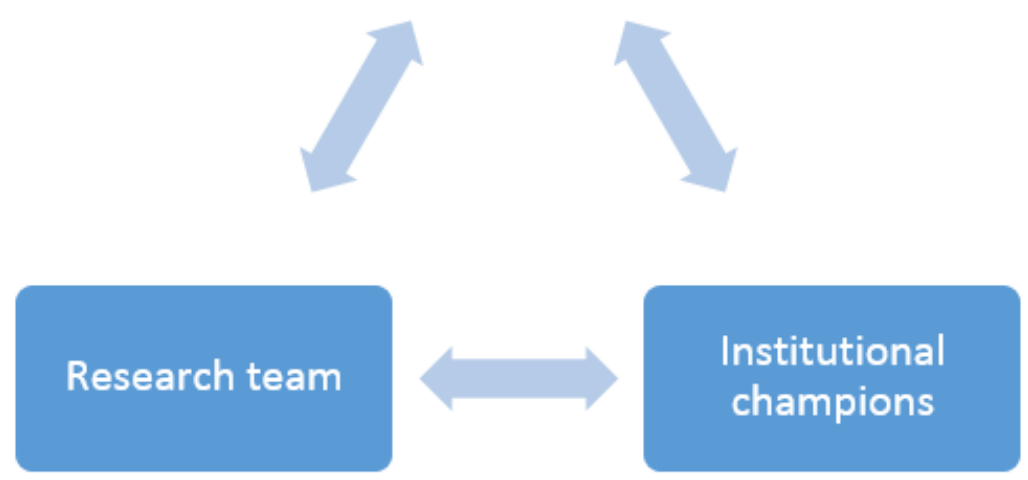

Figure 2. Data collection process for Student Activity and Sport Study Ireland.

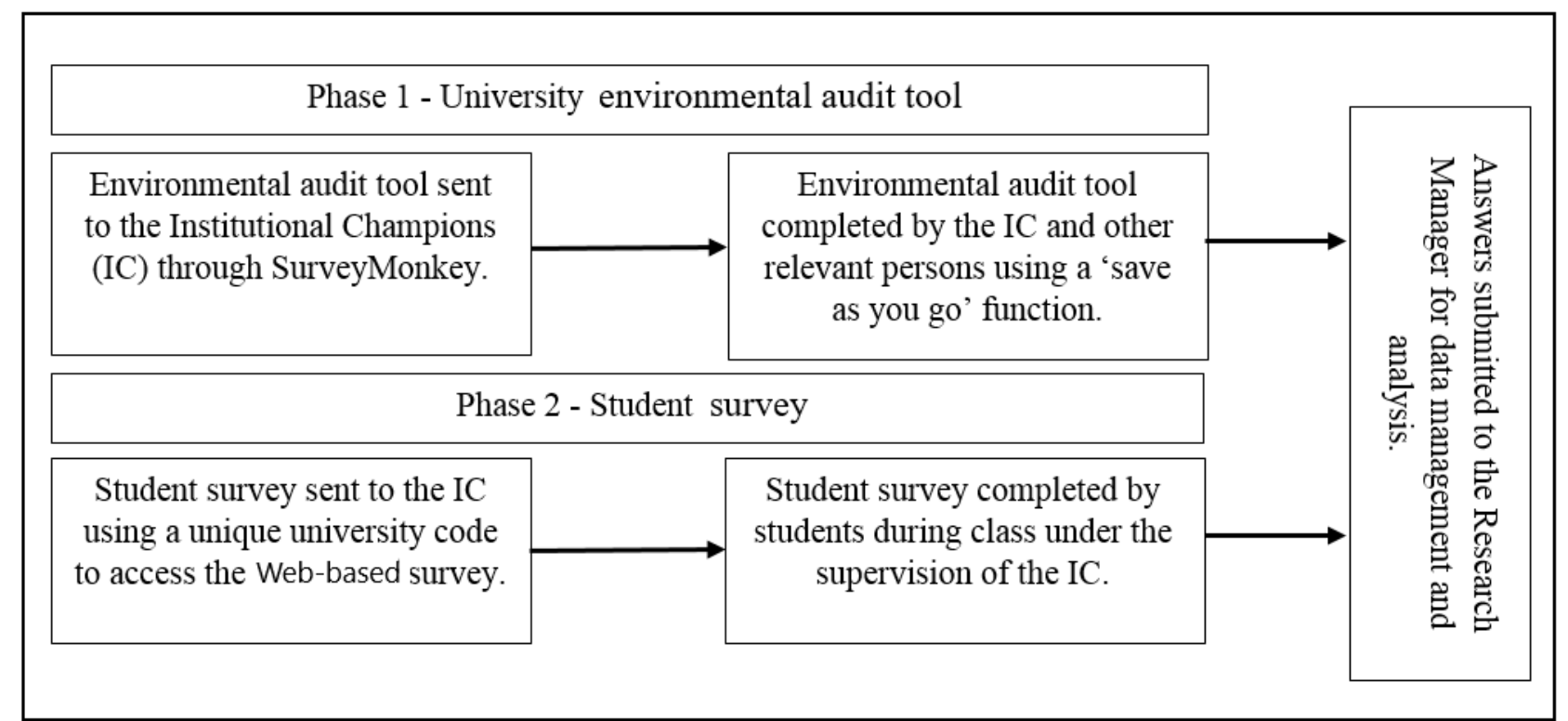




\section{Environmental Audit Tool}

The purpose of the EAT was to provide an analysis of the environment and provision made by universities to support student participation in PA. The EAT consisted of eight sections, with 39 questions addressing the following constructs potentially relevant to university support for PA participation: (1) organizational structures; (2) personnel; (3) facilities; (4) funding or investment; (5) opportunities for participation; (6) high-performance athletic support; and (7) institutional ethos, prioritization, and quality of provision. An initial section gathered information on the respondents (eg, title, contact details, and section responsible for completing).

\section{Environmental Audit Tool Administration and Completion Procedure}

To aid with the distribution and data collection, the EAT was translated into a Web-based instrument using SurveyMonkey (SurveyMonkey Inc, San Mateo, California, USA). The research manager then uploaded the university-specific audit tools, generating a Web-based link for each. This link was sent to the ICs of each participating university via email, who were requested to identify the appropriate personnel in their universities to complete or inform each section. Owing to the time and information required, a save as you go function was applied to the EAT, allowing the participants to save answers and return later. This function also allowed the respondents to edit answers before submitting to the research manager.

\section{Environmental Audit Tool Development}

To guide the development of the EAT, SSI identified the following aspects that should be investigated: (1) local context (eg, location and enrollments); (2) policies and provision; (3) culture (eg, perceived level of support for PA participation); (4) facilities; and (5) needs and resources assessment (eg, current needs and resources to further promote PA). In addition to the above guidance, additional insight into possible content was gained by examining existing literature and other published audits on environments provided by universities in England and Scotland $[25,26]$. Subsequent to the production of the final EAT, an extensive 6-month consultation process took place to further develop, refine, and confirm it. This included consultation with (1) members of the research team and the SSI research management group $(n=10)$; (2) key stakeholders in the PA provision in universities ( $\mathrm{n}=15$, SSI designated contact person); and (3) international experts $(n=3$, personnel involved in the Sports Provision in Scottish Universities and Irish Higher Education Surveys, and a statistician). These consultations were used to review draft versions of the EAT and maximize face validity of the tools used in the EAT. Face validity is seen as the extent to which a measure appears to provide the desired information and is usually assessed by expert consensus [29]. The whole process resulted in the development of a comprehensive EAT, designed to investigate the environment provided by universities to support and promote PA engagement. An overview of the sections included in the EAT is provided below, with the full version available in Multimedia Appendix 1.

\section{Organizational Structure of Physical Activity}

To understand the organizational structures of PA within universities, two questions were asked. First, the number of organizational structures (eg, Department of Sport, sport clubs, and student union) which provide direct support to PA participation, the individual (eg, Director of Sport and student services) within the institution that the organizational structure reports to, and a brief description of the role of the structure were asked about. Second, the nature and number of other partnerships within the institution that support sport and PA participation (eg, health service and disability service) were assessed. Responses were open, allowing the respondents to answer from their universities' perspective.

\section{Personnel}

The EAT included questions regarding (1) the number of full-time employees, part-time employees, and volunteers supporting PA participation in 2009 and 2014 and (2) the relevant staff titles (eg, Director of Sport). This question was answered for each named organizational structure within the university (ie, from previous section). Information regarding training and recognition available to student volunteers was also gathered.

\section{Facilities Provision}

Questions regarding the extent and nature of both indoor and outdoor facilities available to each university at all locations were included in the EAT. Details about the type of facility (eg, courts and pitches), facility dimensions, specifications and number, ownership (owned or hired), and accessibility for individuals with a disability were gathered. A list of named facilities was included $(\mathrm{n}=19)$, and respondents had the option to include other facilities. The section included closed responses (ie, yes or no and owned or hired) and open responses to allow more details about the facilities to be provided. Respondents were asked to complete this section for each location used by their university to provide PA opportunities.

\section{Funding or Investment for Physical Activity}

Investment in PA provision within universities was investigated by gaining insights into the (1) past (last 20 years) and planned (next 5 years) capital investment in facilities by institutional, private, and public sources; (2) current investment in each of the previous 5 years; (3) provision of direct institutional grants for sports clubs; (4) annual fees or charge to students; and (5) student charge to access facility or PA opportunity. Specific funding ranges (eg, up to 25,$000 ; 25,001-35,000$ ) were provided for capital and current investment questions. Open responses were facilitated in the remaining questions.

\section{Student Sport and Physical Activity Participation Provision}

Questions were asked regarding (1) sports clubs provided by the university; (2) the nature of sports clubs provided (ie, type and provision for individuals with a disability); (3) number of participants; (4) description of link between sports clubs and the universities' organizational structures; and (5) participation rates in exercise and fitness opportunities. Additional detail was gathered regarding the competition levels engaged in, level of training hours, staffing, income, and expenditure of clubs. A response was requested for a list of 54 named sports clubs 
(Multimedia Appendix 1), with an option for the respondent to include additional options. The majority of questions were closed in nature, with drop-down menus to facilitate selection of the most appropriate answers.

\section{High-Performance Programs and Athletes}

Questions regarding various aspects of provision for high-performance programs and athletes were included in the EAT. High performance or elite was defined as students currently competing at national or international standards at either senior or junior levels. The following aspects were examined: (1) institutional partnership with national governing bodies of sport and national or international-level sports clubs and (2) provision, nature, source, and value of athletic scholarships and of in-kind athletic support (eg, free access to facilities and sport science support). A combination of open and closed questions was used, and the option of adding other choices was included as appropriate.

\section{Institutional Ethos and Prioritization}

The EAT concluded with questions regarding perceived institutional ethos and prioritization for PA provision. First, respondents were asked about the perceived importance placed on participation in and the promotion of PA and how this importance has changed over the last three years. This was followed by asking about the impact of specific factors (eg, cost of provision and health of students) on the institutional prioritization of PA. Subsequently, the perceived quality of provision under a range of headings (eg, indoor and outdoor facilities, PA opportunities, and funding) for PA was assessed. Finally, the existence and availability of strategic priorities for PA in each university was asked. Likert scales were used to assess the above, with an exception to the final area, which allowed respondents to include a link to any strategic information regarding PA provision.

\section{Data Management of the Environmental Audit Tool}

The responses from SurveyMonkey (SurveyMonkey Inc, San Mateo, California, USA) were directed to an SPSS database version 22 (SPSS Inc). Each university was given a unique identification (ID) number, which allowed the data to be matched across the EAT and SS. To produce a clean and complete dataset, the following steps were followed: (1) successful data transferal from SurveyMonkey (SurveyMonkey Inc, San Mateo, California, USA) to SPSS was confirmed; (2) missing data were identified and appropriately coded; (3) university size was added; and (4) to ensure that the datasets were anonymous, any text that would enable identification of a specific university was edited. The EAT was developed so that provision for each construct by universities could be usefully scored and analyzed. From the EAT, the following key performance indicators (KPIs) were agreed to represent the environment and provision made by universities to support student participation in PA (Multimedia Appendix 2).

An institutional score for total provision and for provision relative to 100 students was calculated for each KPI listed above. The development of the provision score facilitates analysis of total and relative provision for each KPI across small, medium, and large institutions. In addition, it is also possible to categorize universities as making high, medium, and low provision for each KPI. The different categories of provision were determined by calculating a university rank (1-33) for both the total provision score and the total score relative to 100 students. These two ranking values were then summed and ranked to get a composite rank for each university. On the basis of this composite rank, institutions were assigned equally to either a high, medium, or low provision category for each KPI (ie, ranks 1-11=high; ranks 12-22=medium; and ranks 23-33=low). Details regarding calculation of university total provision score for each KPI are provided in Multimedia Appendix 2.

\section{Student Survey}

The purpose of the SS was to provide information of the students' behaviors, beliefs, and attitudes regarding sport and PA. The SS consisted of 8 sections, with 98 questions addressing the following areas: (1) general PA; (2) determinants of PA; (3) volunteering in sport; (4) coaching acquired; (5) sport and recreational PA participation; (6) elite athlete satisfaction; and (7) related health behaviors. Additional questions gathered demographic information about the respondent (eg, sex, age, and household income).

\section{Student Survey Administration and Completion Procedure}

To achieve a nationally representative sample from each university, $3 \%(7 / 32)$ of the student population in large universities, $5 \%(12 / 32)$ of the population in medium-sized universities, and $6 \%(13 / 32)$ of the population in smaller universities were sought. Students were also required from different fields and years of study within each university, depending on the student enrollments [27,28]. Data collection implemented a stratified cluster design for subject selection, stratified by year group and across fields of study, which allowed for a representative sample based on university enrollments. A quota of students needed from each university was developed and given to the IC responsible. The IC then worked alongside the research manager to ensure that the sample was representative of their student body. The IC requested access to the required students and administered the SS during class time, which was completed using the SurveyMonkey software (SurveyMonkey Inc, San Mateo, California, USA). Before the students were given their university-specific survey link, the study was explained, and it was advised that the SS be completed on a laptop, tablet, or mobile phone. The use of a supervised Web-based survey was to maximize response rates, minimize potential for data entry errors, and facilitate the merging of data from over 30 universities. Administering the survey during class time was based on previous research where response rates in excess of $90 \%$ have been achieved [3,30]. To ensure that the ICs collected the data as requested, the date stamp of responses was examined by the research manager. Where the majority of responses (>90\%) occurred in batches and within normal university hours, it was deemed likely that the protocol was adhered to. The ICs were encouraged to collect as many responses as possible. Where the response rate was greater than the quota needed, the research manager drew a random stratified sample to obtain a representative sample for the overall study. This allowed each university to use their own 
full dataset for further local analysis while the quota for the national survey was achieved.

\section{Student Survey Development}

The SS was developed using versions of known tools and measures that have been used in similar studies [23,24,31-33]. The research team consulted with the SSI research management group $(n=7)$, international experts $(n=3$; health professionals), and statisticians $(n=2)$ to develop and refine the SS through a series of drafts $(n=4)$ over a 5-month period. Again, these consultations were used to review draft versions of the survey, generate consensus among experts, and maximize the face validity of the tools used in the SS. The final SS used open and closed questions to gain the relevant responses, with any sensitive questions related to personal or financial circumstances placed at the end of the survey, as they can be a barrier to further survey completion [34]. Filtering was applied throughout the survey so that the relevant questions were asked based on participants' previous responses. An overview of the SS's main sections can be found below, with more information of how the SS was structured, along with the filtering information available in Multimedia Appendix 3.

\section{General Physical Activity}

Students' views of their PA levels were asked using five single-item questions, including (1) if they think they take enough PA to keep healthy; (2) their PA levels compared with others; (3) their PA levels compared with those of last year; (4) increasing PA over the next year; and (5) how important PA opportunities were when enrolling. Responses were recorded using a range of Likert scales and categories. Knowledge of the PA guidelines was asked using a single question, with responses allowed in minutes per week or day. General PA levels were measured using three valid and reliable measurement tools for assessing attainment of the PA guidelines [35]: the International Physical Activity Questionnaire-Short Form [36], an adapted version of the Patient-Centered Assessment andCounselingfor Exercise [37], and a single-item measure [38]. Domains of PA were measured, including PA as a form of transport, cycling, walking, and muscle strengthening exercises. PA as a form of transport was measured using two questions asking about the form of transport used to get to the university and the duration of time it takes [24]. Students who travelled to the university by a motorized form were asked to give three reasons for not actively travelling, with 12 options available. Walking for recreation was measured with a 3 -item question asking about the frequency, duration, and intensity [24]. The frequency and duration of cycling PA [31] and muscle strengthening PA were also assessed using 2-item questions [24].

\section{Determinants of Physical Activity}

The psychosocial determinants of PA participation were assessed using the Determinants of PA Questionnaire (DPAQ) [39]. Shortened from its original for practical purposes, 1 item for each of the 11 determinants was selected based on the items with the highest factor loading from a confirmatory factor analysis [39]. The shortened DPAQ presents 11 statements, worded positively and negatively, asking students to respond using a 7-point Likert scale ranging from strongly disagree to strongly agree. The determinant areas included knowledge, environmental resources, motivation, beliefs about capabilities, emotion, skills, social influences, beliefs about consequences, action planning, coping planning, and goal conflict related to PA.

\section{Volunteering in Sport}

A question asked students if they completed any sports voluntary work in the past four weeks, with responses dichotomized into volunteers and nonvolunteers. Those who volunteered were asked to indicate the duration (hours per week) and type (range of 7 activities) of volunteering both inside and outside the university.

\section{Coaching}

This section asked students if they had received any formal coaching or instruction to improve PA performance in the past four weeks, with responses dichotomized into yes or no. If "yes," then information about where it was accessed was asked with 6 responses provided.

\section{Sport and Recreational Physical Activity Participation}

Student engagement in recreational PA inside their university was assessed by asking "Did you do any sport or recreational PA in the last four weeks?" with four options that acted as filters, categorizing students as "nonparticipants," participating only "within university," "outside university," or "both in and outside university." Each category directed to a specific set of questions designed to find out more about their behavioral choices.

Those in the "within university" and "both" categories were asked about the frequency, intensity, duration, standard, and the type of PA they participate in, with options given for each [33]. These students were asked to rate the top five reasons for participation within their university, with 17 responses provided [40], and their satisfaction with provision for PA by their university using 10-point Likert scales. Students were then asked to indicate the uptake of any new PA since beginning in the university and the highest level that they have participated at, through closed questions [41].

Those in the "outside university" category were asked about the frequency, intensity, duration, standard, and the type of PA they participate in, along with whom they participate. The top three reasons for not participating through the university were asked with an option to suggest what their university could do to encourage participation [33]. Questions regarding the reasons for PA participation, the uptake of new activities, and the highest standard participated were then asked.

Those in the "nonparticipants" category were asked for the three reasons for nonparticipation in any PA, the length of time since they last participated, if they could be encouraged to participate in PA (yes or no), and what would encourage them to participate (13 options) both inside and outside the university [26].

\section{Elite Athlete Satisfaction}

Students who indicated that the highest level participated as "elite" were asked if they received a scholarship or bursary from their university. If "yes," questions about the sufficiency of scholarship, the type of activities participated in, and their satisfaction with the provision for elite athletes by their university followed. 


\section{Related Health Behaviors}

Questions were asked to assess the health-related behavior choices of students. Alcohol intake, smoking, and drug use were all measured using single-item frequency questionnaires [23]. Sedentary behaviors were measured by students to estimate the minutes spent sitting on weekdays and weekends in a range of 8 situations [42]. Dietary habits were measured using two adapted single-item frequency measures, asking about convenience foods (eg, fast food) and fresh foods (eg, fruit and vegetables) [23]. Students' perception of body image, general health in the past 12 months, and happiness were assessed using single-item measures with responses recorded using Likert scales [24,31]. Mental health was measured using the 5-item Mental Health Index, a subscale from the Short Form Health Survey $[43,44]$.

\section{Data Management of the Student Survey}

The sample collected was reviewed against the nationally representative figures once the data collection was complete. This enabled a weighting to be matched to the selection process based on the parameters of age and sex, depending on any gaps or underrepresentation in the initial data collection. The decision to weight by gender and age was based on the knowledge from previous research that participation in sport and PA is significantly influenced by both factors. Weighting of the dataset was completed by statisticians $(n=2)$ and allowed the data to be representative of the national statistics regarding university enrollments. Each dataset was given an ID when data collection was complete, which was the only identifier for each respondent. An ID was also generated based on the university the responses came from, which reflected the ID of the universities in the EAT. This meant the environmental data and SS responses could be matched, allowing examination of the relationship between the university environment and students' responses to the SS. Reliability of data would affect any future analysis; thus, data cleaning and reliability checks were paramount to this phase. This involved checking data for consistency, completeness, and accuracy through spot checks.

\section{Results}

\section{Environmental Audit Tool}

Data collection using the EAT was undertaken between May and August 2014. A total of $80 \%$ (33/41) of universities responded to the EAT. Overall, 70 people from the participating universities played a part in the completion of the EAT, including the following staff or equivalent in each university: Director of Sport; Sports or Clubs and Societies Officer; and Health or PA Promotion Officer. In 42\% (14/33) of institutions, the IC only played a role in the completion of the EAT.

\section{Student Survey}

Data collection using the SS was undertaken between October and December 2014. Students from 78\% (32/41) of universities participated in this phase of the study. Of the 9197 students administered the SS, $88.31 \%(8122 / 9197)$ provided sufficient responses (49.12\% [3966/8122] male; mean 23.17 [SD 6.75] years). Analyses were conducted on the datasets to examine the PA attitudes, beliefs, and behaviors of students and to investigate the influence of relevant factors (ie, individual, behavioral, and environmental) for student PA engagement. The full findings generated from this protocol are available in the SASSI report [45], with additional studies planned in the near future.

\section{Discussion}

\section{Potential of the Protocol}

The SASSI study is a novel, two-phase cross-sectional study combining a purposefully developed EAT and a supervised Web-based SS. Together, the measurement tools provide comprehensive data, which permits an investigation of how personal, behavioral, and environmental factors relate to students' PA. This enables us to have a holistic view of the factors related to behavior as guided by the social cognitive theory and ecological approach used. In addition, the protocol allows the evaluation of the actual environment provided by universities and their association with students' PA. This has the potential to eliminate the gap in the literature regarding the association of the physical environment with PA engagement in students $[10,20]$. The data collection tools developed can be used to evaluate existing university provision for PA and measure change in that provision; interrogate and inform the future research agenda; and provide a platform for the pooling and harmonization of data collected. Finally, the authors believe that this protocol is generalizable and can be used in other nations and by other stakeholders to quantify and evaluate the factors that are important for student PA engagement. Such evaluations will contribute to the impact of health promotion efforts for this population.

\section{Strengths}

The protocol has several strengths, which encourage the possibility of its use in other nations wishing to investigate PA in this population. Identification of similar survey instruments and the consultation process throughout the development phases were strengths that allowed for the creation of 2 assessment tools that were used in over 30 universities across 2 nations. The consultation process in both phases also allowed for face validity to be maximized for the EAT and SS by the research team, management group, and international experts. Both the EAT and SS are comprehensive in assessing their intended areas but are designed to be used together, which provide a unique dataset. This unique dataset has the potential to increase our understanding of the actual environment provided by universities and the effects it has on students' PA, while also assessing personal and behavioral factors. Other major strengths of the SASSI protocol concern the training, buy-in, and input from the ICs throughout both phases and the success of administering the EAT and SS through a Web-based platform. These strengths were key factors for the high response rates in the EAT ( $80 \%$ of universities invited completed the EAT) and SS $(88.31 \%$; 8122/9197) of the 9197 students administered the SS sufficiently completed it). For phase 2, the use of a supervised survey delivered during class time replicated the response rates of similar study protocols $[3,30]$. 


\section{Limitations}

Although the SASSI protocol possesses strengths, the weaknesses also need to be recognized here and addressed for future research. The EAT and SS required a great deal of information and were time-consuming. This magnifies the importance of the buy-in from the ICs and the features offered through Web-based administration (eg, stop-save and ease of administration), which aided completion. Additional limitations concerning the questions used in the EAT and SS need to be addressed. Despite both tools being comprehensive, certain questions and options offered may have resulted in responses that do not provide all the information needed. For example, in the EAT, capital and current investment were assessed using closed questions with the lowest option being "up to $€ 25,000$." This meant that universities that invested $€ 25,000$ were grouped with others who invested zero, with no way for the research team to tell the difference. In addition, in the SS, certain health-related behavior questions (eg, alcohol and smoking) assessed frequency but not the intensity of the behavior (eg, units of alcohol or cigarettes). The primary focus of SASSI was PA, which meant less importance was put on other questions, but this is still a limitation of this protocol. Suggestions for future research may be to provide additional options in the closed questions or offer open responses instead. Finally, the validity and reliability of some measures included have not been acquired for this population, with certain measures used in the SS shortened and adapted for practical reasons and to reduce the burden on students. Evidence suggests that lengthy measurement tools lead to greater amounts of missing data on individual questions, decreased variability in answers to grid-based questions, and shorter responses to open-ended questions [46]. Although the methodology allows for face validity of the measures used in the EAT and SS to be maximized through the use of known measures, a consultation phase and training days, there may be a need for future research to test their concurrent validity and reliability. A further weakness of the SASSI protocol was the cross-sectional design that meant the correlates of PA could be measured, but not the true determinants.

\section{Conclusions}

Nevertheless, the authors believe that the SASSI protocol, with its whole country approach, is unique and can be used as a model for other nations hoping to investigate the PA and its related factors in university students. The use of one standardized comprehensive protocol to study such a topic would lead to the harmonization of data, allowing for the comparison of findings across countries. The information collected using the SASSI protocol may have potential uses such as providing information to relevant stakeholders and policy makers, providing strategic guidance for future policy and planning of university settings and university health interventions to enhance the health, well-being, and sustainability of students. The authors also hope that the tools developed in SASSI can be used in future longitudinal research, hoping to investigate the personal, behavioral, and environmental determinants of PA in university students.

\section{Acknowledgments}

The authors would like to thank all members of the SASSI research team, with a special mention for the institutional champions who worked hard to ensure the success of the study.

\section{Authors' Contributions}

JJM developed a plan for this protocol and acted as an institutional champion for the SS. CM, MHM, NM, and CBW developed the overall protocol for SASSI and acted as coauthors for this paper. NB acted as the research manager for SASSI.

\section{Conflicts of Interest}

None declared.

\section{Multimedia Appendix 1}

Environmental audit tool.

[PDF File (Adobe PDF File), 810KB-Multimedia Appendix 1]

\section{Multimedia Appendix 2}

Computation for each key performance indicator stemming from the environmental audit tool responses.

[PDF File (Adobe PDF File), 143KB-Multimedia Appendix 2]

\section{Multimedia Appendix 3}

Student survey including the filtering process.

[PDF File (Adobe PDF File), 437KB-Multimedia Appendix 3]

\section{References}


1. Epton T, Norman P, Sheeran P, Harris PR, Webb TL, Ciravegna F, et al. A theory-based online health behavior intervention for new university students: study protocol. BMC Public Health 2013 Feb 5;13:107 [FREE Full text] [doi: 10.1186/1471-2458-13-107] [Medline: 23384237]

2. Murray D, Adams T, Banks M, Bundesen C, Burns D, Clayton D, International Education Association of Australia (IEAA). In: Davis D, Mackintosh B, editors. Making a Difference: Australian International Education. Sydney: University of New South Wales Press; Apr 1, 2012:352.

3. Haase A, Steptoe A, Sallis JF, Wardle J. Leisure-time physical activity in university students from 23 countries: associations with health beliefs, risk awareness, and national economic development. Prev Med 2004 Jul;39(1):182-190. [doi: 10.1016/j.ypmed.2004.01.028] [Medline: 15208001 ]

4. Epton T, Norman P, Dadzie AS, Harris PR, Webb TL, Sheeran P, et al. A theory-based online health behaviour intervention for new university students (U@Uni): results from a randomised controlled trial. BMC Public Health 2014 Jun 5;14:563 [FREE Full text] [doi: 10.1186/1471-2458-14-563] [Medline: 24903620]

5. Department of Health and Children, Health Service Executive. 2009. The National Guidelines on Physical Activity for Ireland URL: http://health.gov.ie/wp-content/uploads/2014/03/active guidelines.pdf [accessed 2019-01-12] [WebCite Cache ID 75NSCZUOS]

6. World Health Organization. Physical Activity - Fact Sheet URL: http://www.euro.who.int/en/health-topics/disease-prevention/ physical-activity/data-and-statistics/physical-activity-fact-sheets [accessed 2018-04-19] [WebCite Cache ID 6ynXQK6d9]

7. Reiner M, Niermann C, Jekauc D, Woll A. Long-term health benefits of physical activity--a systematic review of longitudinal studies. BMC Public Health 2013 Sep 8;13:813 [FREE Full text] [doi: 10.1186/1471-2458-13-813] [Medline: 24010994]

8. Lee I, Shiroma EJ, Lobelo F, Puska P, Blair SN, Katzmarzyk PT, Lancet Physical Activity Series Working Group. Effect of physical inactivity on major non-communicable diseases worldwide: an analysis of burden of disease and life expectancy. Lancet 2012 Jul 21;380(9838):219-229 [FREE Full text] [doi: 10.1016/S0140-6736(12)61031-9] [Medline: 22818936]

9. Hallal PC, Andersen LB, Bull FC, Guthold R, Haskell W, Ekelund U, Lancet Physical Activity Series Working Group. Global physical activity levels: surveillance progress, pitfalls, and prospects. Lancet 2012 Jul 21;380(9838):247-257. [doi: 10.1016/S0140-6736(12)60646-1] [Medline: 22818937]

10. Keating XD, Guan J, Piñero JC, Bridges DM. A meta-analysis of college students' physical activity behaviors. J Am Coll Health 2005;54(2):116-125. [doi: 10.3200/JACH.54.2.116-126] [Medline: 16255324]

11. Clemente FM, Nikolaidis PT, Martins FM, Mendes RS. Physical activity patterns in university students: do they follow the public health guidelines? PLoS One 2016 Mar 29;11(3):e0152516 [FREE Full text] [doi: 10.1371/journal.pone.0152516] [Medline: 27022993]

12. Bandura A. Social Foundations Of Thought And Action: A Social Cognitive Theory. New Jersey: Prentice Hall; Oct 11, 1985:640.

13. Rovniak LS, Anderson ES, Winett RA, Stephens RS. Social cognitive determinants of physical activity in young adults: a prospective structural equation analysis. Ann Behav Med 2002;24(2):149-156. [doi: 10.1207/S15324796ABM2402] [Medline: 12054320]

14. Farren GL, Zhang T, Martin SB, Thomas KT. Factors related to meeting physical activity guidelines in active college students: a social cognitive perspective. J Am Coll Health 2017;65(1):10-21. [doi: 10.1080/07448481.2016.1229320]

15. Sallis JF, Owen N, Fisher E. Ecological models of health behavior. In: Glanz K, Rimer BK, Viswanath K, editors. Health Behavior and Health Education: Theory, Research, and Practice. California: Jossey-Bass; 2008:465-482.

16. McLeroy KR, Bibeau D, Steckler A, Glanz K. An ecological perspective on health promotion programs. Health Educ Q 1988;15(4):351-377. [Medline: 3068205]

17. Deliens T, Deforche B, De Bourdeaudhuij I, Clarys P. Determinants of physical activity and sedentary behaviour in university students: a qualitative study using focus group discussions. BMC Public Health 2015 Feb 28;15:201 [FREE Full text] [doi: 10.1186/s12889-015-1553-4] [Medline: 25881120]

18. Choi J, Lee M, Lee J, Kang D, Choi JY. Correlates associated with participation in physical activity among adults: a systematic review of reviews and update. BMC Public Health 2017 Apr 24;17(1):356 [FREE Full text] [doi: 10.1186/s12889-017-4255-2] [Medline: 28438146]

19. Reed JA, Phillips DA. Relationships between physical activity and the proximity of exercise facilities and home exercise equipment used by undergraduate university students. J Am Coll Health 2005;53(6):285-290. [doi: 10.3200/JACH.53.6.285-290] [Medline: 15900992]

20. Johnson LG. LSU Digital Commons, LSU Doctoral Dissertations. 2006. Physical activity behavior of university students: an ecological approach URL: https://digitalcommons.lsu.edu/gradschool_dissertations/1556/ [accessed 2018-04-19] [WebCite Cache ID 6ynXyGO51]

21. Leslie E, Sparling PB, Owen N. University campus settings and the promotion of physical activity in young adults: lessons from research in Australia and the USA. Health Educ 2001;101(3):116-125. [doi: 10.1108/09654280110387880]

22. Hope A, Dring C, Dring J. Drugs and Alcohol. 2005. College Lifestyle and Attitudinal National (CLAN) Survey URL: https://www.drugsandalcohol.ie/4327/1/2670-2853.pdf [accessed 2018-04-19] [WebCite Cache ID 6ynYKuGdv] 
23. Morgan K, McGee H, Watson D, Perry I, Barry M, Shelley E, et al. Dublin: Department of Health and Children. 2008 Jan 1. SLAN 2007: survey of lifestyle, attitudes \& nutrition in Ireland: main report URL: https://epubs.rcsi.ie/cgi/viewcontent. cgi? article=1002\&context=psycholrep [accessed 2018-04-19] [WebCite Cache ID 6ynYUzacu]

24. Woods CB, Moyna N, Quinlan A, Tannehill D, Walsh J. School of Health and Human Performance, Dublin City University and The Irish Sports Council, Dublin, Ireland. 2010. The Children's Sport Participation and Physical Activity Study (CSPPA Study). Research Report No 1 URL: https://www.ucd.ie/t4cms/CCLSP Study Report1.pdf [accessed 2018-04-19] [WebCite Cache ID 6ynYgfzsj]

25. Taylor J. Edinburgh Sport Scotland. 2003 Jan 1. An Audit of Sports Provision in the Higher Education Sector in Scotland URL: https://www.stir.ac.uk/research/hub/publication/709869 [accessed 2019-01-12] [WebCite Cache ID 75Na5HS1y]

26. Lambley C. Sport England. 2004 Mar 15. Audit of sports provision in the higher education sector URL: https://www. sportengland.org/media/3435/higher-education-exec-summary-1.pdf [accessed 2018-04-19] [WebCite Cache ID 6ynZwDvhV]

27. Higher Education Authority. 2014. Key facts and figures. Higher Education 2013/14 URL: http://hea.ie/assets/uploads/ 2017/06/Key-Facts-and-Figures-201314.pdf [accessed 2018-04-19] [WebCite Cache ID 6yna5ktkj]

28. Department for Employment and Learning. 2014 Feb 13. Enrolments at UK higher education institutions: Northen Ireland analysis 2012/2013 URL: https://www.economy-ni.gov.uk/publications/

enrolments-uk-higher-education-institutions-northern-ireland-analysis-2012-2013 [accessed 2019-01-12] [WebCite Cache ID $75 \mathrm{NaS6a04}]$

29. Kelly P, Fitzsimons C, Baker G. Should we reframe how we think about physical activity and sedentary behaviour measurement? Validity and reliability reconsidered. Int J Behav Nutr Phys Act 2016 Mar 1;13:32 [FREE Full text] [doi: 10.1186/s12966-016-0351-4] [Medline: 26931142]

30. Patterson E, McGeough D, Cannon E, Hagströmer M, Bergman P, Kearney J, et al. Self-efficacy, stages of change and physical activity in Irish college students. J Public Health 2006 Apr;14(2):81-86. [doi: 10.1007/s10389-006-0028-6]

31. Sport Northern Ireland. 2010. Adult Sport and Physical Activity Survey 2010. A Baseline Report URL: http://www. sportni.net/sportni/wp-content/uploads/2013/03/SAPASReport.pdf [accessed 2019-01-12] [WebCite Cache ID 75NaurTcx]

32. Harmon D, Foubert O. Higher Education Authority. 2013. Eurostudent Survey V Report on the Social and Living Conditions of Higher Education Students in Ireland 2013 URL: https://www.ucd.ie/t4cms/Eurostudent\%20Survey\%20V\%20Report. pdf [accessed 2018-04-19] [WebCite Cache ID 6ynaXH8E0]

33. Sport England. 2012. Higher Education Sport Participation and Satisfaction Survey. National Report Year One URL: https:/ /www.sportengland.org/media/4271/higher-education-sport-participation-and-satisfaction-national-year-one-report.pdf [accessed 2018-04-19] [WebCite Cache ID 6ynahR8Me]

34. Colton D, Covert RW. Designing and Constructing Instruments for Social Research and Evaluation. San Francisco, CA: John Wiley \& Sons; 2007:412.

35. Murphy JJ, Murphy MH, MacDonncha C, Murphy N, Nevill AM, Woods CB. Validity and reliability of three self-report instruments for assessing attainment of physical activity guidelines in university students. Meas Phys Educ Exerc Sci 2017;21(3):134-141. [doi: 10.1080/1091367X.2017.1297711]

36. Craig CL, Marshall AL, Sjöström M, Bauman AE, Booth ML, Ainsworth BE, et al. International physical activity questionnaire: 12-country reliability and validity. Med Sci Sports Exerc 2003 Aug;35(8):1381-1395. [doi: 10.1249/01.MSS.0000078924.61453.FB] [Medline: 12900694]

37. Prochaska JJ, Sallis JF, Long B. A physical activity screening measure for use with adolescents in primary care. Arch Pediatr Adolesc Med 2001 May;155(5):554-559. [Medline: 11343497]

38. Milton K, Bull FC, Bauman A. Reliability and validity testing of a single-item physical activity measure. Br J Sports Med 2011 Mar;45(3):203-208 [FREE Full text] [doi: 10.1136/bjsm.2009.068395] [Medline: 20484314]

39. Taylor N, Lawton R, Conner M. Development and initial validation of the determinants of physical activity questionnaire. Int J Behav Nutr Phys Act 2013 Jun 11;10:74 [FREE Full text] [doi: 10.1186/1479-5868-10-74] [Medline: 23758912]

40. European Commission. 2014 Mar. Special Eurobarometer 412: sport and physical activity; report URL: http://ec.europa.eu/ commfrontoffice/publicopinion/archives/ebs/ebs_412_en.pdf [accessed 2019-04-19] [WebCite Cache ID 6ynarsxPD]

41. Hardie Murphy M. Dublin City University. 2016. CSPPA Plus: a 5-year longitudinal study of children's sport and physical activity participation URL: http://doras.dcu.ie/21386/ [accessed 2018-04-19] [WebCite Cache ID 6ynb0I621]

42. Marshall AL, Miller YD, Burton NW, Brown WJ. Measuring total and domain-specific sitting: a study of reliability and validity. Med Sci Sports Exerc 2010 Jun;42(6):1094-1102. [doi: 10.1249/MSS.0b013e3181c5ec18] [Medline: 19997030]

43. Ware JE, Snow KK, Kosinski M, Gandek B, New England Medical Center hospital. The Health Institute. SF-36 Health Survey: Manual and Interpretation Guide, The Health Institute. Boston: The Health Institute, New England Medical Center, 1993; 1993.

44. Houghton F, Keane N, Murphy N, Houghton S, Dunne C. Tertiary level students and the Mental Health Index (MHI-5) in Ireland. Irish J Appl Soc Stud 2011 Jan 1;10(1):40-48. [doi: 10.21427/D75Q81]

45. Murphy MH, Murphy N, MacDonncha C, Woods C, Byrne N, Ferguson K, et al. Student Sport Ireland. 2015. Student Activity and Sports Study Ireland (SASSI) URL: http://www.studentsport.ie/wp-content/uploads/2016/02/ SASSI-Full-Report-Without-Appendices..pdf [accessed 2018-04-19] [WebCite Cache ID 6ynbNzr9F] 
46. Galesic M, Bosnjak M. Effects of questionnaire length on participation and indicators of response quality in a web survey. Public Opin Q 2009 Jan;73(2):349-360. [doi: 10.1093/poq/nfp031]

\author{
Abbreviations \\ DPAQ: Determinants of Physical Activity Questionnaire \\ EAT: environmental audit tool \\ IC: institutional champion \\ ID: identification \\ KPI: key performance indicator \\ PA: physical activity \\ SASSI: Student Activity and Sport Study Ireland \\ SS: student survey \\ SSI: Student Sport Ireland
}

\author{
Edited by G Eysenbach; submitted 19.04.18; peer-reviewed by L Becker, J Spence; comments to author 02.09.18; revised version \\ received 26.10.18; accepted 26.10.18; published 21.02.19 \\ Please cite as: \\ Murphy JJ, Woods CB, Murphy MH, Murphy N, Byrne N, Mac Donncha C \\ Student Activity and Sport Study Ireland: Protocol for a Web-Based Survey and Environmental Audit Tool for Assessing the Impact \\ of Multiple Factors on University Students' Physical Activity \\ JMIR Res Protoc 2019;8(2): 10823 \\ URL: $\underline{\text { http: } / / w w w . r e s e a r c h p r o t o c o l s . o r g / 2019 / 2 / e 10823 /}$ \\ doi: $10.2196 / 10823$ \\ PMID: 30789352
}

CJoseph J Murphy, Catherine B Woods, Marie H Murphy, Niamh Murphy, Neal Byrne, Ciaran Mac Donncha. Originally published in JMIR Research Protocols (http://www.researchprotocols.org), 21.02.2019. This is an open-access article distributed under the terms of the Creative Commons Attribution License (https://creativecommons.org/licenses/by/4.0/), which permits unrestricted use, distribution, and reproduction in any medium, provided the original work, first published in JMIR Research Protocols, is properly cited. The complete bibliographic information, a link to the original publication on http://www.researchprotocols.org, as well as this copyright and license information must be included. 